\title{
Health and Local Community Response to COVID-19 in Saudi Arabia
}

\author{
Fahad Alsultan ${ }^{1,2}$ Nouf Alabdulkarim ${ }^{3} \quad$ Raidah S. Albaradie ${ }^{4} \quad$ Shahid Bashir $^{4}$
}

${ }^{1}$ King Saud Medical City, Riyadh, Saudi Arabia

2Prince Sultan Military Medical City, Riyadh, Saudi Arabia

${ }^{3}$ College of Medicine, King Saud University, Riyadh, Saudi Arabia

${ }^{4}$ Neuroscience Center, King Fahad Specialist Hospital, Dammam, Saudi Arabia

J Health Allied Sci ${ }^{\mathrm{NU}}: 2021 ; 11: 110-111$

In late December 2019, an unexplained case of viral pneumonia occurred in Wuhan, China, which later became known as coronavirus disease 2019 (COVID-19), caused by severe acute respiratory syndrome coronavirus 2 (SARSCoV-2). ${ }^{1,2}$ In the first week of March 2020, its epicenter shifted from China to Italy, and most European states and the United States are now severely affected. Human COVID-19 infections have posed a major threat to the international health system and economy ${ }^{1,2}$ As per the World Health Organization, on November 17, there were approximately 55.4 million confirmed cases, with a case fatality rate of $2.4 \%{ }^{3}$ The present outbreak of COVID-19 has markedly affected many countries, including the United States with $11,538,280$ confirmed cases (case fatality rate: $1.18 \%$ ), Brazil 5,876,740 (2.82\%), Russia 1,971,013 (1.72\%), United Kingdom 1,390,681 (3.74\%), India 8,874,918 (1.47\%), and Saudi Arabia 101,914 (1.6\%). ${ }^{3}$ Saudi Arabia is the most populous country in the Gulf state, with 32.94 million people. It has the second largest human population in the Arab world and the fifth largest in Asia. However, COVID-19's incidence and mortality rates are very low in Saudi Arabia. The reason could be the efficient and effective measures put in place, which people responded to well.

From the beginning of the outbreak, containing SARS-CoV-2 and not transmitting it around the globe posed a near-impossible challenge. The outbreak was first recognized in Saudi Arabia in early March, and large-scale containment efforts started in mid-March. The government of Saudi Arabia has released multiple statements and enacted several measures to control the COVID-19 pandemic, starting with the suspension of entry for Umrah, a religious duty performed by Muslims in their holy cities of Mecca and Medina, on February 27.
Address for correspondence Shahid Bashir, PhD, Neuroscience Center, King Fahad Specialist Hospital, Dammam 32253, Saudi Arabia (e-mail: shahidbpk13@gmail.com).

On March 2, the first case in Saudi Arabia of a citizen arriving to Qatif from Iran through Bahrain was confirmed. On March 4, it became mandatory for all passengers coming from countries affected by the COVID-19 outbreak to be screened at the airport. On March 7, the total cases in Saudi Arabia reached 7, all of which were in Qatif, and schools and universities in Qatif were suspended. A few days later entry into and exit from Qatif were temporarily suspended. In addition, a COVID-19-negative polymerase chain reaction report was requested upon arrival to Saudi Arabia. Later that week, the Minister of Education suspended all schools and universities in Saudi Arabia. With 62 confirmed cases, all social events were suspended, as was attendance at workplaces in government agencies and private sectors and prayer in all mosques except the two holy mosques. As the number of confirmed cases started to increase drastically, curfew from 7 p.m. to 6 a.m. in all cities was mandated across Saudi Arabia ( - Fig. 1) 1,4 On March 29, a total of 1,299 cases were confirmed, with 8 deaths, which warranted a change in the curfew start time in Riyadh, Makkah, and Medina to 3:00 p.m. and suspension of entry into and exit from all cities ( - Fig. 1).

Age distribution may play a role in the low case fatality rate in Saudi Arabia, where it is estimated to have 3.63\% of the population to be 65 years and above. In contrast, in the countries with the highest case fatality rate like Italy having $22.08 \%$ of the population aged 65 and more and a case fatality rate of 3.8. ${ }^{5}$

COVID-19 incidence is high but case fatality rate remains very low in Saudi Arabia, perhaps due to these strict measures and people following the instructions from the Ministry of Health in dealing with the pandemic.

\section{Conflict of Interest}

None declared. published online January 24, 2021
DOI https://doi.org/

$10.1055 / \mathrm{s}-0040-1722803$ ISSN 2582-4287.
(C) 2021. Nitte (Deemed to be University).

This is an open access article published by Thieme under the terms of the Creative Commons Attribution-NonDerivative-NonCommercial-License, permitting copying and reproduction so long as the original work is given appropriate credit. Contents may not be used for commercial purposes, or adapted, remixed, transformed or built upon. (https://creativecommons.org/licenses/by-nc-nd/4.0/).

Thieme Medical and Scientific Publishers Pvt. Ltd. A-12, 2nd Floor, Sector 2, Noida-201301 UP, India 


\section{COVID-19 progression in Saudi Arabia}

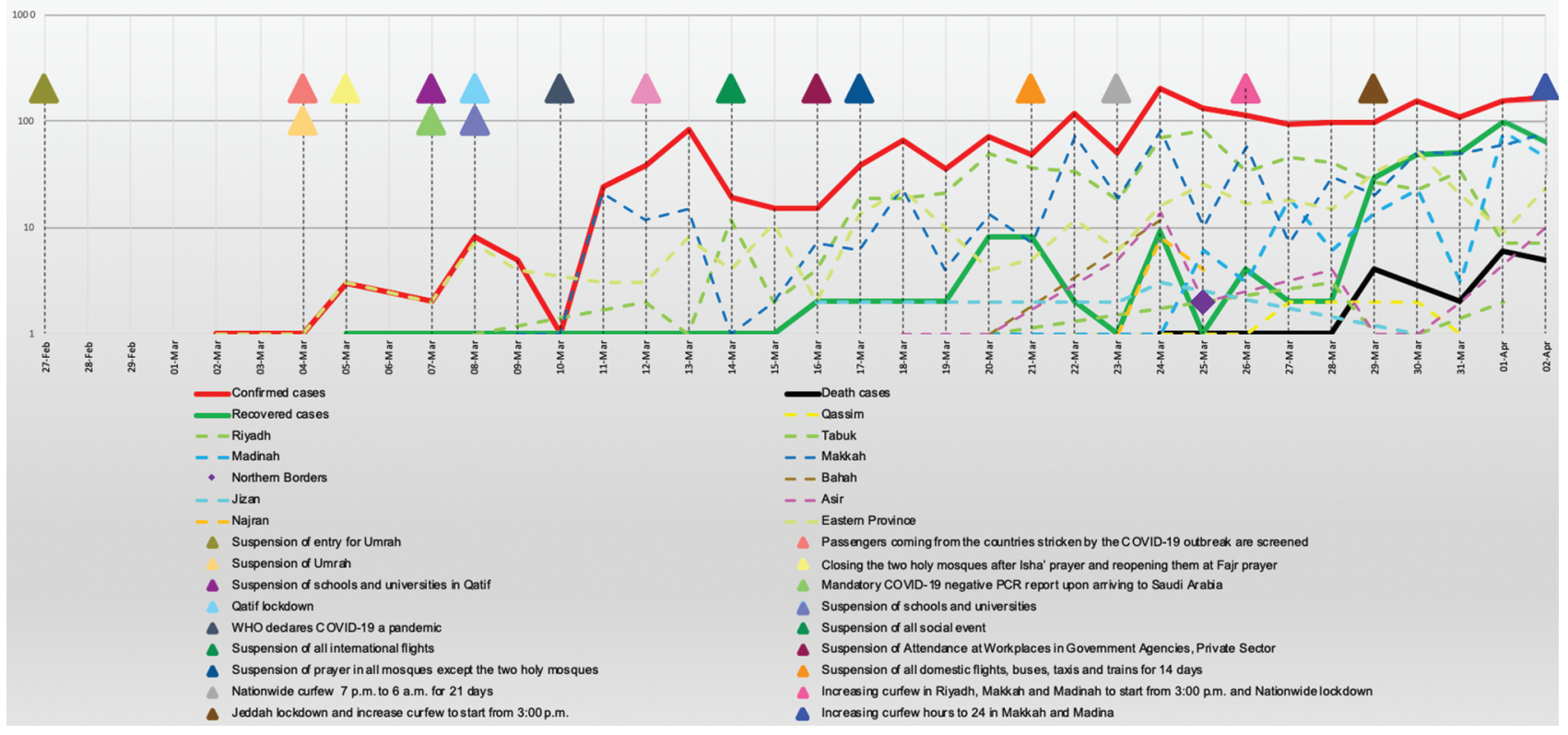

Fig. 1 Coronavirus disease 2019 (COVID-19) progression in Saudi Arabia with each region.

\section{References}

1 World Health Organization. Coronavirus disease (COVID-19) technical guidance: 251 laboratory testing for 2019-nCoV in humans. Available at: https://www.who.int/emergencies/ diseases/novel-coronavirus-2019/technical-guidancepublications. Accessed January 4, 2021

2 World Health Organization. Available at: https://www.who. int/emergencies/diseases/novel-coronavirus-2019. Accessed November 17, 2020

3 Coronavirus Update (Live): 55,469,884 Cases and 1,334,699 Deaths from COVID-19 Virus Pandemic - Worldometer
Available at: https://www.worldometers.info/coronavirus/. Accessed November 17, 2020

4 Saudi Press Agency. 2020. General News. Available at: https:// www.spa.gov.sa/listnews.php?lang $=$ en $\&$ cat $=9 \#$ page $=1$. Accessed April 1, 2020

5 Listing F. Age structure - The World Factbook - Central Intelligence Agency Available at: https://www.cia.gov/library/ publications/the-world-factbook/fields/341.html. Accessed November 17, 2020 